\title{
A STUDY OF THE COGWITIVE LEVEL AND SOME BASIC SKILLS IN BASKETBALL AMONG SECONDARY STUDENTS ACCORDING TO GENDER AND INTELLIGEMCE VARIABLES
}

\author{
Ahcene Ahmed, Mokrani Djamel, Benzidane Houcine \\ University of Mostaganem, Institute of Physical Education and Sports, \\ Laboratory of Programs Optimization in Physical Activity and Sports, Algeria \\ Address for corpespondence: \\ Djamel Mokrani \\ Laboratory of Programs Optimization in Physical Activity and Sports \\ Route natoinale N 11, kharouba, 27-000 Mostaganem, Algeria \\ E-mail:djamel.mokrani@univ-mosta.dz
}

Ahstract The curriculum of physical education and sports through sports activities programmed in the secondary stage seeks to achieve a set of goals of mobility, cognitive and socio-emotional to serve the goals of physical education and sports at this stage. We find a basketball game one of these activities which need a degree of intelligence and knowledge that helps in developing the skill level of the students and selecting the teacher for the appropriate exercises to teach different basic skills. In this context, our study aims to measure the cognitive level of the students of the third secondary level, as well as their level in some basic skills. The study was conducted using a cognitive test in basketball and the selection of some technical tests according to the objectives of the curriculum, then comparing the level according to the sex variables and the level of intelligence and interaction between them and identifying the relationship between these variables. One of the students of the third year secondary school in the city of Mostaganem (Algeria), and after the statistical treatment of the results was reached the results of the most important:

1. The absence of a gender effect and the level of logical and physical intelligence and interaction between them at the cognitive level while being influenced by the level of space intelligence in favor of those with high intelligence.

2. There is a difference in the level of skill of pointing, scrolling and dialogue for the benefit of males, and there is no impact on the level of intelligence, whether logical or physical or space.

3. There is an impact of the interaction between sex and the level of spatial intelligence at the cognitive level, where males and females with high intelligence showed more response.

4. The interaction of sex and the level of intelligence, whether logical, physical or spatial, has no impact on the skills of correction, scrolling and dialogue.

5. There is a direct correlation between $I Q$ and cognitive level as well as basic skills in basketball.

Key Worlls cognitive level, some basic skills in basketball, secondary students, intelligence variables 


\section{Introduction}

The cognitive outcomes associated with any sporting activity have become recognized in contemporary societies that are experiencing economic, social and sporting prosperity because of their obvious contribution in helping the individual to understand the issues surrounding them. The thinker Phoenix points out that one of the symptoms of contemporary cultural decay is the intellectual aspects of education. There is a clear chapter on the physical aspects, although physical education and sports in principle offer the best opportunity for personal progress, as a whole process, in harmony. It is obtained by the means of games, in which intelligence, skill, aesthetic imagination, social sensitivity, and morality make the effort worthwhile and purposeful. Hara mentioned the value of the cognitive field of sport and physical education. He pointed out that the training and teaching of mental cognitive abilities has been an indispensable part of learning stages of sport. The most successful trainers are aware of the importance of mental and cognitive aspects and they have planned to impart theoretical knowledge to learners. As Welgos pointed, the general educational goals are transformed into direct educational goals focused on three types of human behavior (cognitive, dynamic, emotional). This classification format provides a useful tool for determining the contents of the curriculum, so that the topics of learning are selected more efficiently in physical education.

The measurement of knowledge objective evaluation methods are used alongside tests that measure physical and skillful aspects (AI Said, 2001). Scientific research has shown that all cognitive tests are among the most widely used, if not the most widely used, assessment tools (Hassanein, 1995). Cognitive processes at the beginning are often predominated by motor skills training, but basic information about skills should also be provided to the students properly.

Acquiring knowledge and using it while learning or during sports competition in basketball requires some intelligence to facilitate this process. Intelligence as an ability to think, understand, innovate and solve problems and issues that are encountered by the individual is essential in acquiring mathematical knowledge and use it appropriately and purposefully while performing skill during the learning process, or during the competition in basketball, where the intelligence factor enables the individual to use their mental and physical abilities in the performance of the skills with less strength and ability of mobility and speed with minimal effort (Jabbar, 2011).

The skills involved include balance, motor synergy, speed, flexibility and a sense of movement in order to solve a problem. Complex and multiple situations during sports competitions require a high degree of intelligence to deal with different expectations and make appropriate decisions within the playing field, and this applies to the game of basketball, which is characterized by complex laws and a small arena and a small circle of correction, and here contributes high intelligence to overcome the difficult and quick situations in a correct and appropriate manner during learning and training.

Basketball game is characterized by rapid focus and understanding of the different relationships given the nature of different situations in order to perform accordingly to the information provided and to understand the relationship between all the elements with insight into the results of their performance. The ability to apply the motor duty accurately is also of high importance. Based on the above, the subject of the study was limited in the attempt to identify the relationship between the level of knowledge and some basic skills in basketball according to the level of intelligence and gender in the students who pass the baccalaureate (17-18) years. 


\section{Research Objectives}

1. To measure the level of knowledge in basketball for third-year students, differentiated sex and level of intelligence, by building a cognitive knowledge test that allows students to be classified.

2. To measure the level of performance in the basic skills in basketball (third-year students) by gender and level of intelligence through the selection of skill tests to suit the content of the ministerial curriculum for physical education and sports in the secondary stage in terms of level and possibilities available for application.

3. To recognize the level of knowledge of the impact of interaction between sex and level of intelligence at the level of knowledge and the level of skill of correction and scrolling and dialogue in basketball at the third year secondary students.

\section{Research Methodology}

Due to the nature of the subject, we relied on the survey as a descriptive approach.

\section{The research sample}

The study sample included 60 students from the third year of secondary school; 30 males and 30 females of the 2017/2018 academic year. They were randomly selected, in addition to the 60 students who applied the cognitive test in its preliminary form after the approval of a number of experts to extract the difficulty and discrimination coefficients of the test words.

\section{Study tool}

The questionnaire and the personal interview were used to determine the technical tests and build the cognitive test. Three tests that measure some of the basic skills in basketball were selected among the nine tests that were presented to 10 experts in the Institute of Physical Education and Sports Specialists in basketball.

An objective test was built to measure the level of knowledge in basketball according to the ministerial program scheduled for the third year secondary, where the test included 120 questions. After its presentation to the experts, 20 questions were canceled and the test of 100 words was applied to a sample of 60 students from the third year secondary to extract the difficulty and discrimination factors. Accordingly, 37 statements were canceled and the final examination was made up of 63 words about 6 aspects: skill, schematic aspect, hardware and tools, laws and rules, physical aspect and arbitration.

Howard Gardner's multi-intelligence test was also used to determine in particular logical intelligence, physical intelligence and spatial intelligence. The students were classified according to three levels: high, intermediate and low level. 


\section{Presentation and discussion of the results}

\section{Comparison by gender and logical intelligence level}

Table 1 presents that:

1. There is a statistical significance of the gender variable at level 0.05 in the skills of correction and scrolling and at the level of 0.01 in the skill of dialogue for the benefit of males with no statistical indication of the level of knowledge.

2. There is a lack of statistical significance in the level of knowledge and level of basic skills according to the logical intelligence variable.

3. There is no statistical indication of the interaction between logical intelligence and gender at the cognitive level and basic skills, except for the skill of scrolling as illustrated in Figures 1, 2, 3 and 4.

Table 1. Comparison of the level of knowledge and basic skills by gender and the level of logical intelligence

\begin{tabular}{|c|c|c|c|c|c|c|}
\hline & Source of variation & Total squares & Degree of freedom & Average squares & F calculate & Significance \\
\hline \multirow{4}{*}{$\begin{array}{l}\text { The cognitive } \\
\text { level }\end{array}$} & Between the sexes & 8.98 & 01 & 8.98 & 1.38 & Non significant \\
\hline & Between levels of intelligence & 10.77 & 02 & 5.38 & 0.82 & Non significant \\
\hline & Interaction & 13.05 & 2 & 6.52 & 0.89 & Non significant \\
\hline & In the groups & 394.83 & 54 & 7.31 & - & \\
\hline \multirow{4}{*}{ Shooting } & Between the sexes & 42.83 & 01 & 42.83 & 7.16 & 0.05 \\
\hline & Between levels of intelligence & 8.14 & 02 & 4.07 & 2.28 & Non significant \\
\hline & Interaction & 3.57 & 02 & 1.78 & 0.29 & Non significant \\
\hline & In the groups & 331.5 & 54 & 6.14 & - & \\
\hline \multirow{4}{*}{ Passing } & Between the sexes & 21.43 & 01 & 21.43 & 5.62 & 0.05 \\
\hline & Between levels of intelligence & 5.3 & 02 & 2.65 & 6.79 & 0.01 \\
\hline & Interaction & 0.78 & 02 & 0.39 & 0.10 & Non significant \\
\hline & In the groups & 212.82 & 54 & 3.94 & - & \\
\hline \multirow{4}{*}{ Dribbling } & Between the sexes & 28.21 & 01 & 28.21 & 16.69 & 0.01 \\
\hline & Between levels of intelligence & 3.01 & 02 & 1.5 & 1.03 & Non significant \\
\hline & Interaction & 2.91 & 02 & 1.45 & 0.85 & Non significant \\
\hline & In the groups & 92.16 & 54 & 1.71 & - & \\
\hline
\end{tabular}

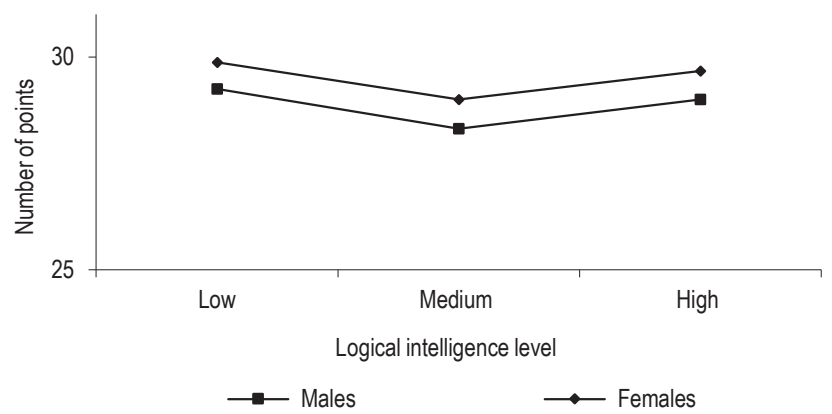

Figure 1. Interaction between gender and the level of logical intelligence at the cognitive level 


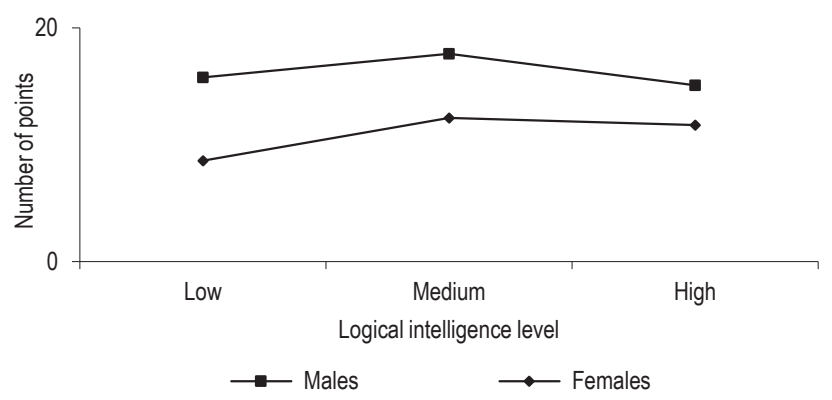

Figure 2. Interaction between sex and the level of logical intelligence in the skill of shooting

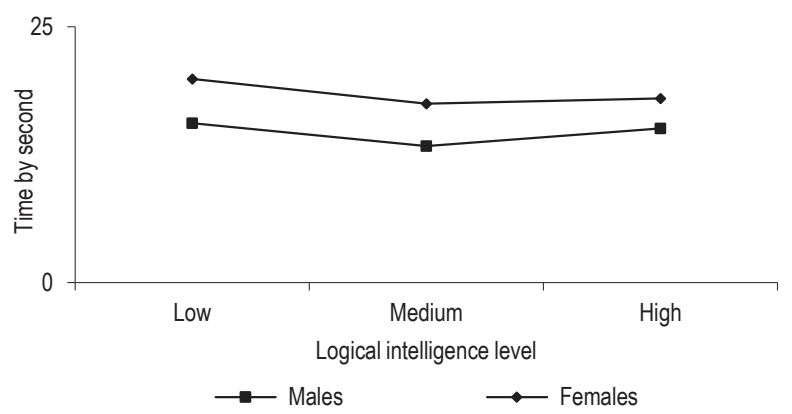

Figur 3. Interaction between sex and the level og logical intelligence in the skill of passing

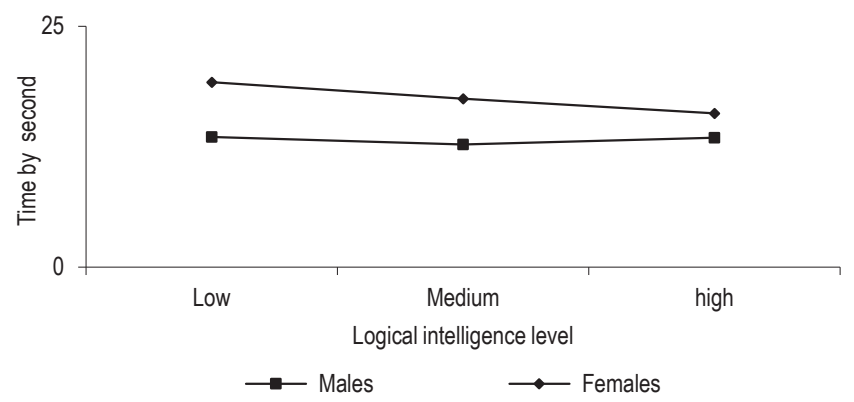

Figure 4. Interaction between sex and the level of logical intelligence in the skill of dribbling

We conclude from the above that:

1. The level of knowledge of students is not affected by the gender variable and the level of logical intelligence nor the interaction between these two variables.

2. The level of skills of correction, scrolling and dialogue was influenced by the gender variable in favor of males, and was not affected by the level of logical intelligence except the skill of scrolling, where males with higher IQs showed better results. 
3. The level of knowledge and basic skills were not affected by the interaction between sex and level of intelligence.

\section{Comparison by gender and level of physical intelligence}

Table 2 presents that:

1. There is a statistical indication of the gender variable at the level of 0.01 in the basic skills (correction, scrolling and dialogue) in favor of males with no statistical significance at the cognitive level.

2. There is no statistical indication of the level of physical intelligence in the cognitive level and the level of basic skills.

3. There is no statistical indication of the interaction between physical and motor intelligence at the cognitive level and basic skills.

Table 2. Comparison in the level of knowledge by sex and level of physical intelligence

\begin{tabular}{|c|c|c|c|c|c|c|}
\hline Tests & Source of variation & Total squares & Degree of freedom & Average squares & F calculate & Significance \\
\hline \multirow{4}{*}{$\begin{array}{l}\text { The cognitive } \\
\text { level }\end{array}$} & Between the sexes & 7.13 & 01 & 7.13 & 2.85 & Non significant \\
\hline & Between levels of intelligence & 11.15 & 02 & 5.57 & 2.23 & Non significant \\
\hline & Interaction & 10.12 & 02 & 5.06 & 2.02 & Non significant \\
\hline & In the groups & 135.01 & 54 & 2.50 & - & \\
\hline \multirow{4}{*}{$\begin{array}{l}\text { Shooting from } \\
\text { specific areas }\end{array}$} & Between the sexes & 46.04 & 01 & 46.04 & 7.90 & 0.01 \\
\hline & Between levels of intelligence & 4.64 & 02 & 2.32 & 0.40 & Non significant \\
\hline & Interaction & 4.54 & 02 & 2.27 & 0.38 & Non significant \\
\hline & In the groups & 322.04 & 54 & 5.96 & - & \\
\hline \multirow{4}{*}{$\begin{array}{l}\text { Passing and } \\
\text { receiving the ball }\end{array}$} & Between the sexes & 32.44 & 01 & 32.44 & 13.68 & 0.01 \\
\hline & Between levels of intelligence & 6.63 & 02 & 3.13 & 1.32 & Non significant \\
\hline & Interaction & 0.85 & 02 & 0.42 & 0.17 & Non significant \\
\hline & In the groups & 131.87 & 54 & 2.44 & - & \\
\hline \multirow{4}{*}{ Dribbling speed } & Between the sexes & 23.79 & 01 & 23.79 & 15.15 & 0.01 \\
\hline & Between levels of intelligence & 4.00 & 02 & 2.00 & 1.27 & Non significant \\
\hline & Interaction & 2.63 & 02 & 1.32 & 0.83 & Non significant \\
\hline & In the groups & 85.52 & 54 & 1.58 & - & \\
\hline
\end{tabular}

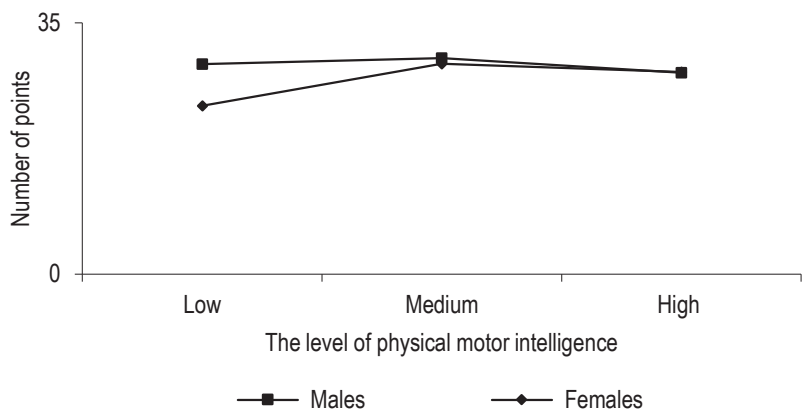

Figure 5 . Interaction between sex and the level of physical intelligence at the cognitive level 


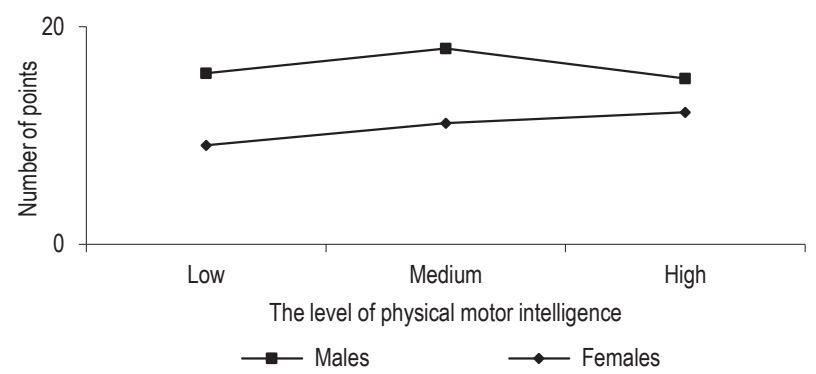

Figure $\boldsymbol{b}$. Interaction between sex and the level of physical intelligence in the level of shooting

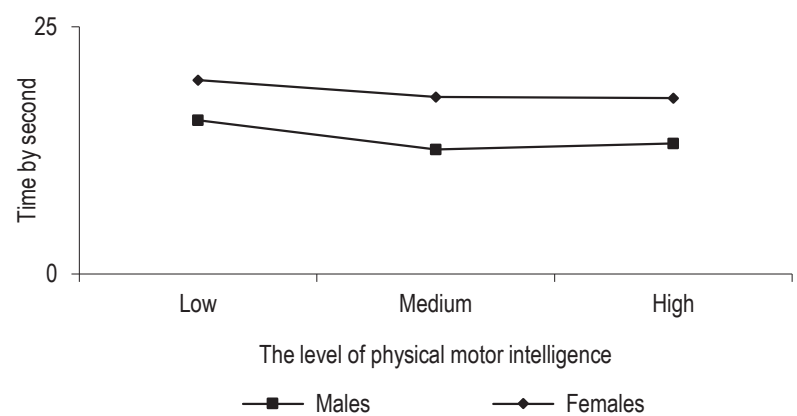

Figure 7. Interaction between sex and the level of physical intelligence in the level of passing

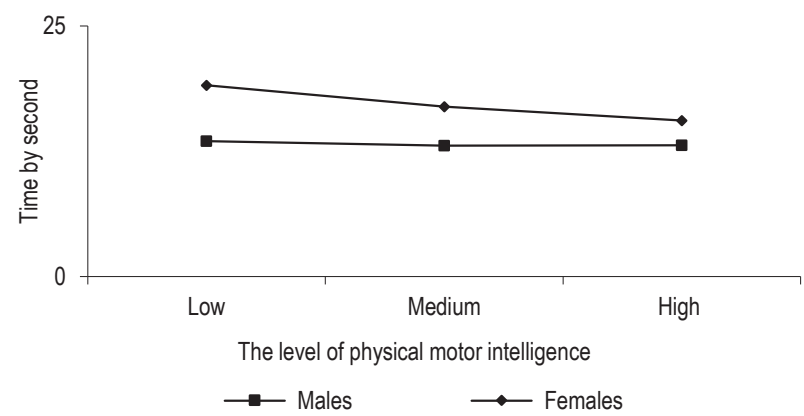

Figure 8. Interaction between sex and the level of physical intelligence in the dribbling level

We conclude from the above that:

1. The level of knowledge and the level of physical intelligence of males and females, and the interaction between them was not affected.

2. There is a difference in the level of skill of correction, scrolling and dialogue according to the sex variable for the benefit of males, and there is no effect on the level of physical intelligence as well as interaction between him and sex. 


\section{Comparison between males and females by level of spatial intelligence}

Table 3 presents that:

1. There is a statistical significance between levels of intelligence at the cognitive level in favor of high IQ, and there is no statistical significance according to gender variable.

2. There is a statistical significance in the basic skills between the sexes in favor of males.

3. There is a statistical significance of the interaction between sex and level of intelligence in the level of knowledge in basketball for the benefit of males and females with high IQ.

4. There is no statistical significance of the interaction between sex and the level of intelligence in the level of basic skills in basketball.

Table 3. Comparison in the level of knowledge by sex and level of spatial intelligence

\begin{tabular}{|c|c|c|c|c|c|c|}
\hline Tests & Source of variation & Total squares & Degree of freedom & Average squares & F calculate & Significance \\
\hline \multirow{4}{*}{$\begin{array}{l}\text { The cognitive } \\
\text { level }\end{array}$} & Between the sexes & 9.17 & 01 & 9.17 & 1.56 & Non significant \\
\hline & Between levels of intelligence & 155.15 & 02 & 77.57 & 13.26 & 0.01 \\
\hline & Interaction & 50.1 & 02 & 25.05 & 4.28 & 0.05 \\
\hline & In the groups & 316.13 & 54 & 5.85 & - & \\
\hline \multirow{4}{*}{ Shooting } & Between the sexes & 47.26 & 01 & 47.26 & 8.26 & 0.01 \\
\hline & Between levels of intelligence & 3.79 & 02 & 1.90 & 0.33 & Non significant \\
\hline & Interaction & 5.73 & 02 & 2.86 & 0.49 & Non significant \\
\hline & In the groups & 314.52 & 54 & 5.82 & - & \\
\hline \multirow{4}{*}{ Passing } & Between the sexes & 34.41 & 01 & 34.41 & 16.23 & 0.01 \\
\hline & Between levels of intelligence & 7.35 & 02 & 3.67 & 1.73 & Non significant \\
\hline & Interaction & 0.59 & 02 & 0.30 & 0.14 & Non significant \\
\hline & In the groups & 118.02 & 54 & 2.18 & - & \\
\hline \multirow{4}{*}{ Dribbling } & Between the sexes & 23.44 & 01 & 23.44 & 15.22 & 0.01 \\
\hline & Between levels of intelligence & 4.46 & 02 & 2.23 & 1.45 & Non significant \\
\hline & Interaction & 2.80 & 02 & 1.40 & 0.9 & Non significant \\
\hline & In the groups & 83.36 & 54 & 1.54 & - & \\
\hline
\end{tabular}

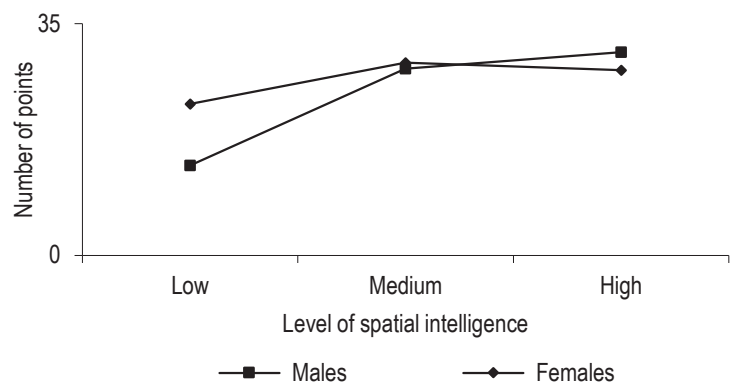

Figure $\mathrm{S}$. Interaction between sex and the level of spatial intelligence at the cognitive level 


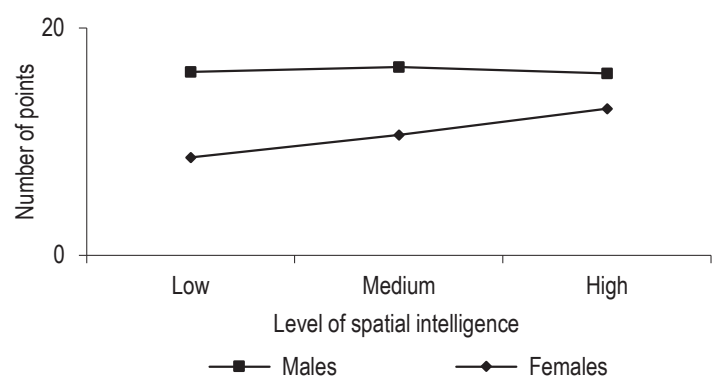

Figur 10. Interaction between gender and the level of spatial intelligence in the skill of shooting

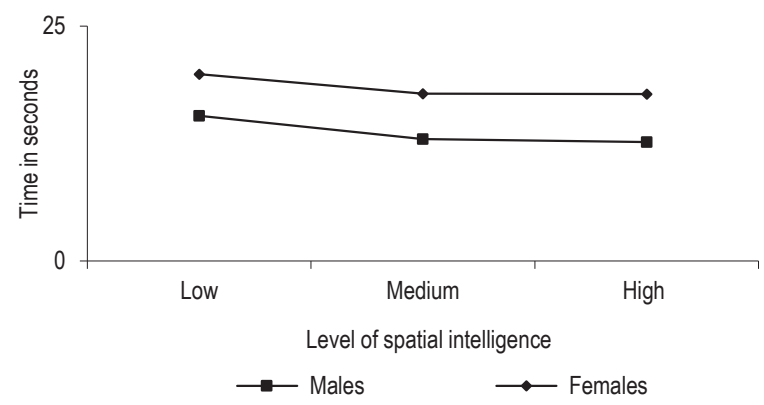

Figure 11. Interaction between sex and the level of spatial intelligence in the skill of scrolling

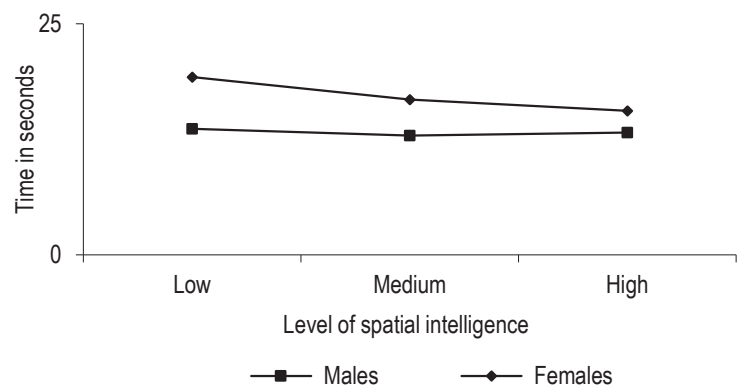

Figure 12. Interaction between gender and the level of spatial intelligence in the skill of dribbling

We conclude from the above that:

1. There is an impact of the level of space intelligence at the cognitive level in favor of medium and high intelligence, with no trace of sex influence.

2. There is an impact of the interaction between sex and the level of space intelligence on the cognitive level, as males and females with higher $I Q$ have shown more response. 
3. There is a difference in the skill level of correction for males, and there is no effect on the level of spatal intelligence nor interaction between this and sex.

\section{A study of the relationship hetween intelligence, cognitive level and basic skills}

Table 4 presents a statistical significance of correlation coefficients at the level of 0.05 and 0.01 , which means that there is a positive relationship between IQ types and cognitive level, as well as basic skills in basketball.

Table 4. The relationship between intelligence types, cognitive level and level of basic skills in basketball

\begin{tabular}{lcccc}
\hline \multicolumn{1}{c}{ Intelligence type/skill } & The cognitive level & Shooting & Passing & Dribbling \\
\hline Zonal & $0.55^{* *}$ & $0.35^{*}$ & $0.41^{*}$ & $0.62^{* *}$ \\
Body & $0.36^{*}$ & $0.37^{*}$ & $0.38^{*}$ & $0.57^{* *}$ \\
Spatial & $0.42^{*}$ & $0.46^{*}$ & $0.40^{*}$ & $0.60^{* *}$ \\
\hline
\end{tabular}

${ }^{*} \mathrm{D}$ at $0.05 ;{ }^{*} \mathrm{D}$ at 0.01 .

\section{Discussion}

The results of the study indicate that there is a positive relationship between the types of intelligence (logical, physical, motor, spatial) and basic skills as well as the level of knowledge in basketball, with the impact of sex and intelligence and interaction between them. These results ephasize the importance of teaching according to multiple intelligence types in order to improve the process of teaching and talent discovery. This approximates the results of the K. M. Sarouphim's studies (1997; 2002), which showed the importance of estimation according to different intelligences, and also the study of Y. Reid et al. (1999), which showed the importance of evaluation performance on the activities of solving problems based on the theory of multiple intelligences in the students, and the study of Abdul Rahman Nasser and Ghadir Star Abbas (2016), which showed the existence of the relationship between physical intelligence and handling skills and correction and discretion in basketball.

The researchers believe that pupils representing multiple intelligence types, which is one of the most important mental abilities, must characterize basketball players in order for them to address the rhythms of rapid movement as well as accuracy. This is valid especially in the case of goal correction, which requires using at least three types of intelligence to be performed successfully. Motor intelligence and - characterized by this type of intelligence - the ability to use parts of the body skillfully during a performance require knowledge of the body and sense of movement and balance, strength, speed and flexibility (Cooper, 2008). The advantage of this intelligence ability is making one able to gain knowledge through physical sensation and lead the movements well.

Spatial intelligence requires visual sensation as much as it requires awareness and the ability to think with images. The one who has this type of intelligence has the ability to think in mental images.

In the game of basketball students need to think when implementing correction, for example, by taking responsibility and showing self-confidence in order to achieve a successful correction. According to the types by Novell (2010), the ability of self-discrepancy in terms of strengths and weaknesses, also awareness of internal mix and motives and self-esteem, if combined with these types of intelligence working together allows for implementation 
of the skills that are especially difficult. The harder the skill required, the most number of types of intelligence have to engage.

\section{Conclusions}

1. There is an absence of a gender effect and the level of logical and physical intelligence and interaction between them at the cognitive level while the level of spatial intelligence is affected in favor of high intelligence.

2. There is a difference in the level of skill of pointing and scrolling and dialogue for the benefit of males, and there is no impact on the level of intelligence, whether logical, physical or spatial.

3. There is an impact of the interaction between sex and the level of spatial intelligence at the cognitive level, where males and females with high intelligence showed more response.

4. Gender interaction and the level of intelligence, whether logical, physical or spatial, have no impact on the skills of correction, scrolling and dialogue.

5. There is a direct correlation between the types of intelligence and cognitive level as well as basic skills in basketball.

\section{References}

Abdul Sattar Jabbar (2011). Mathematical Intelligence. Amman: Zahran Publishing House.

Amin al-Khuli, Mahmoud Adnan (1990). Physical Education School. Cairo: Arab Thought House.

Amin Anwar Al-Khouli (1990). Sport and society. Cairo: The World of Knowledge Series.

Armstrong, T. (2008). Multiple intelligence in the classrom. Alexandria, Virginia : Association for Prevision and Curriculum Developement. Cabrini, M. (1999). The Psychology of Soccer. Spring City, PA: Reedswain.

Coakley, J. (1997). Sport in Society. Issues and Controversies. 5th Edition. Times Mirror/Mosby College.

Eccles, J.S., Harold, R.D. (1991). Gender differences in sport involvement: Applying Eccles' Expectancy-Value Model. Journal of Applied Sport Psychology, 3, 7-35.

Gardner, H. (1999). Intelligence - Reframed - Multiple intellgences for the 21st century. New York: Basic Books.

Gardner, H. (1997). Multiple intelligences as partner in school improve. Educational leadership, 55 (1).

Hara (1975). Origins of Sports Training. Mosul: Dar Maaref.

Huffman and others (1996). Psychology in action. Intelligence and intelligence testing. New York.

Jaber Abdul Hamid Jaber (1979). Education and education technology. Cairo: Arab Renaissance House.

Kleingeld, A., Mierlo, H., Arends, L. (2011). The effect of goal setting on group performance: A meta-analysis. Journal of Applied Psychology, 96 (6), doi: 10.1037/a0024315.

Kyllo, L.B., Landers, D.M. (1995). Goal setting in sport and exercise: A research synthesis to resolve the controversy. Journal of Sport and Exercise Psychology, 17, 117-137.

Lindley, L.D. (2001). Personality and unpublished human ph.d. thesis. University of Lows: Retrieved from: www.lip.umi.com/dissertation. Mohammed Al-Hamahmi Amin Al-Kholi (1990). The foundations of building sports education programs. Cairo: Arab Thought House.

Mohammed Subhi Hassanein (1995). Measurement and Evaluation in Physical Education and Sports. Cairo: Arab Thought House.

Morgan, H. (1992). Analysis's of Gardner's theory of multiple intelligence. The Annual Meeting of the Eastern Educational Research Association.

Rejoice of Mr. Layla (2001). Mathematical cognitive measurement. Cairo: Dar Al Ma'aref.

Shebenou, R.J. Johnsen, S.K. (1990). Test of Nonverbal Intelligence: A Language-free measure of cognitive ability, examiner's manuel Second Edition. Austin: Pro-ed. 
Weinberg, R. Gould, D. (2003). Foundations of Sport and Exercise Psychology. Illinois: Human Kinetics, pp. 222-223.

Yperen, N.W.V., Blaga, M., Postmes, T. (2014). A Meta-Analysis of Self-Reported Achievement Goals and Non-self-Report Performance across Three Achievement Domains (Work, Sports, and Education).

Yukelson, D. (1998). Communicating effectively. In. J. Williams (ed.) Sport Psychology: Personal growth to peak performance (pp. 142157). CA: Mountain View, Myfield.

Cite this article aS: Ahmed, A., Djamel, M., Houcine, B. (2019). A Study of the Cognitive Level and Some Basic Skills in Basketball Among Secondary Students According to Gender and Intelligence Variables. Central European Journal of Sport Sciences and Medicine, 3 (27), 5-16. DOI: 10.18276/cej.2019.3-01. 